\title{
Un documento arqueológico del año 1828
}

\author{
J. Mascaró passarius
}

Este texto manuscrito de Vicente Furió sobre su exploración y hallazgos arqueológicos en la zona del Palmer de Campos, que en forma de carta remitió al anticuario e historiador Joaquín María Bover fue un preciado obsequio personal que me hizo don Juan Llabrés Bernal, el cual lo habia heredado de su padre el insigne erudito con Gabriel Llabrés y Quintana.

Transcribimos literalmente esta carta, incluso con sus faltas de ortografía. Falta acentuación en todas las palabras donde las lleva, y no utiliza la letra "h" donde debe: "aver, allazgo, ay, allado, ora", poniendola, en contra, donde no debe, "hadmirado". Pero esta cuestión tiene aquí poca importancia, pero hemos querido respetar el texto en toda su integridad. Lo interesante del texto es su fecha, bien temprana, en que fue escrito, y los dibujos de la parte principal de los materiales arqueológicos obtenidos por Furió en el Palmer de Campos y en Ses Salines, donde opinaba vehementemente, estaba situada la ciudad romana de Palma. Nos queda la duda de si una de las lápidas descritas, falsa, fue obra del propio Furió o si fue una falsificación que endosaron al presbítero Bonet.

\section{Campos 18 de Dici. $^{\text {e }}$ de 1828}

Dn. Joaquin, muy Sr. mio: quisiera hoy aver tenido la complacensia de que conmigo hubiese visto los entierros de nuestros insignes Romanos Baleares, cuyos cadaveres yacen de distintos modos enterrados en este cementerio de las Salinas pueblo contiguo al Palmer que tantas disputas ha acarreado a nuestos historiadores. Una casualidad ha motivado el allazgo de diferentes monumentos antiguos cual es, la de posor a Campos con un mi amigo llamado D. Pedro Ant ${ }^{\circ}$ Sala, Pro. y colegial 
del C. N. ${ }^{a}$ S. ${ }^{a}$ de la Sapiencia para ver la Balsa de la fuente Santa, que es la laguna de aguas termales cuya Analisis hizo hace muchos años el físico del Regto. de Borbón; ${ }^{1}$ y nuestro actual Intendente quiere ponerla en orden con los edificios necesarios para la comodidad de los dolientes que quieran acudir á esta nueva Picina. Sea lo que se fuere que todo anda entre opiniones y ay quien predica las Virtudes de estas aguas al paso que otros ponen muchos ostaculos para que pueda llevarse á efecto la proyectada obra. Despues de haber visto las inmensas praderas, pantanos, Estanques y demas produciones naturales con que abundan estos confines, pasamoa a ver las Salinas y el puerto de Campos ${ }^{2}$ donde despues de haber admirado nuestra Cabrera ${ }^{3}$ que se presenta á su frente con su adjunta la Tiquadra patria del famoso Anibal ${ }^{4}$, nos detuvimos en sus playas y arenales ${ }^{5}$ á recoger diferentes mariscos para formar las colecciones que le tengo indicadas. Regresados á Campos tuve noticia que en el Pueblo de las Salinas se habian allado cosas muy preciosas y envié luego un propio á aquel lugar para que informado de la verdad del hecho me trajese algo de los hallazgos que se pudieran havér. La mañana siguiente se vino con un pedazo de verniz sacado de una mina ${ }^{6}$ y me dijo que esto era lo que se habia hallado pero que el capellán D. Guill. ${ }^{\circ}$ Bonet Pro. de aquel Pueblo tenia una moneda romana de plata y que otros sujetos tenian otras de cobre. Luego partimos luego dicho Sala Pr. ${ }^{\circ}$ y yo y llegamos con 1 hora y ${ }^{1} / 2$ á las Salinas dejamos los cavallos en casa del Sr. Pro. Bonet el cual me regaló luego la moneda indicada que halló en aquellos campos la que es consular y tiene á la una parte la testa de la Piedad y en la otra un triunfo, la que vera $\checkmark$. cuando yo regrese á esa. Las noticias que por nuestros historiadores

' Se trata del doctor en medicina y cirujano D. Juan Andrés Nieto, que en 1805 publicó el análisis de las aguas del Estany de ses Estaques, del Salobrar, donde según Furió "se ven volar el Flamenco, el Pato, Anades, Garzas, Gavinas y el Cisne, del que escribe D. Buenaventura Serra que en su tiempo (1777) aparecieron mas de doscientos en aquel punto".

${ }^{2}$ Situado al extremo meridional de la Platja des Trenc, donde aún se ven restos de un malecón, aunque hay quien supone que estuvo en el actual puerto pesquero de la Colònia de Sant Jordi, próxima al Trenc.

${ }^{3}$ Grupo de islas situadas al sur de Mallorca, perfectamente visibles desde sus costas meridionales. La principal es Cabrera, siguiéndoles la Conillera y Redona.

${ }^{4}$ El mismo Furió en su "Carta histórico-crítica sobre el lugar donde estuvo situada la antigua Palma en la época que los romanos dominaron la isla de Mallorca", Palma (Imp. Guasp, 1835, pág. 15), explica que se basa en Plinio, "Nat. Hist." vol. 3... "Majore XII M. passum in altum habet Capraria insidiosa naufragiis et a regione Palmae urbis Menariae et Tiquadra et Parva Annibalis".

${ }^{5}$ Se trata con toda probabilidad de la playa del Trenc.

- Se refiere a la entrada de un monumento megalítico o romano, e incluso de una cueva prehistórica subterránea. 
y antiquarios tenia de la existencia de un Sementerio ${ }^{7}$ de Romanos en aquellos lugares me obligó á informarme y luego hise cavar en algunos puntos y encontramos en el primer hoyo que sería de 8 palmos de profundidad un sepulcro cubierto á su izquierda en la misma piedra que llamamos Amarés ${ }^{8}$ y dentro encontramos 14 "hidritas" como las de los nos. $1 .^{\circ}$ y $2 .^{\circ} \mathrm{del}$ mismo tamaño y fabricadas de barro. El cadaver estaba tendido y hemos hadmirado la integridad del cráneo y de la mayor parte de los huesos mayores. Visto que nada mas se ofrecia de particular en este sepulcro ya tenia mandado cavar en dos que no estavan muy distantes en los que hemos hallado al primero, junto á la cabeza del difunto un jarro de barro que es el que figura el $n .{ }^{\circ} 3$, un vaso de vidrio $n .^{\circ} 4$ y una Escudilla de barro n. ${ }^{\circ} 6$. En el contiguo entierro hallamos unos pocos huesos y junto a la cabeza del muerto un vaso de vidrio $n .^{\circ} 7$, y a sus pies un plato de barro muy bien fabricado. Los naturales de este Pueblo tienen guardadas algunas monedas de cobre las que me van presentando para ver si las quiero comprar y todas las que he visto he comprado, de las que hay diferentes del tiempo del Consulado y otras del Imperio. Una lápida con una pila de 2 palmos y $1 / 2$ de largo y 1 y $1 / 2$ de ancho que servia de urna á las cenizas de un Romano me ha regalado el Pro. Bonet que sera creo de su adceptacion cuando la vea y al interin quiero ponerla aquí para no privar a $\mathrm{V}$. aunque sea por pocos dias de tener la satisfacción a leerla y expositar su sentido y si tiene ocasión (que si creo la tendra) remitirla a su amigo Dr. D. Ant. ${ }^{\circ}$ Ramis y Ramis a quien venero y aprecio sin conocerlo para que nos desentrañe el sentido de ella como á tan versado en este Ramo de historia. La lapida dice:

$$
\begin{aligned}
& \text { D. M. S. JVS: } \ldots . \\
& \text { COS . P. CS P... } \\
& \text { PALMAE . } \\
& \text { M. V. D. }
\end{aligned}
$$

Despues de haber pasado otra vez a Campos he de Porreras en cuya Villa hemos estado estos dias y en la cual tenia dado orden que se cavase en un campo donde me aseguraton que continuamente se halla-

7 De la magnitud de este cementerio puede darnos idea la descripción que da del mismo Furió en su "Carta histórico-critica" citada, pág. 26: "en el mes de diciembre de 1828 cuando me presentaron en un dilatado cementerio, (del Palmer), que era capaz para contener los cadáveres ordinarios de una población de más de cincuenta mil almas".

" Piedra arenisca, o "marés" en el idioma catalán insular.

${ }^{9}$ El doctor CRISTOFOR VENY: “Corpus de las inscripciones baleáricas hasta la dominación árabe", CSIC, Del. Roma, 1965, pág. 249, dice que la publicó Hübner (CIL II, 369) entre las falsas. Veny confirma el juicio de Hübner con argumentos arqueológicos y paleográficos, demostrándose así sin lugar a dudas, la falsedad de esta inscripción. 
ban fracmentos y antiguedades Romanas, dos lamparas que son del $\mathrm{n} .{ }^{\circ}$ 8 , un lacrimatorio, n. ${ }^{\circ} 9$, las primeras de barro, y este de vidrio con algunos trozos de lampara de bronce muy bien trabajada aunque tan mal conservada que no puedo tomar su configuración por esto no se la remito dibujada.

En esta Villa hay un presbitero que me ha regalado la alaja de bronce $n .{ }^{\circ} 10$ la que creo seria algun ofertorio o mas bien copa de incienso lo que convendria consultar con dicho mi Sr. Ramis y una pieza de barro muy tosca que es la del $n^{\circ} 11$ y algunas monedas todas Imperatorias que no puedo describir por estar muy llenas de tierra y con el tiempo espero limpiar para colocar en mi monetario.

Parece que la fortuna me persigue en este genero de hallazgos lo que mas bien atribuyo á la abundancia de este genero de antiguedades en estos campos que á mi dicha. Otra y mas buena remesa se me acaba de hacer ahora en el acto mismo de escribir esta por el Pro. Bonet consistente en un cantaro que es el $n . .^{\circ} 12$ de unos dos palmos de alto hallado en el lugar de Sevall, dos lamparas que son los $n .^{\circ} 13$ y 14 la primera tiene en la parte inferior una inscripción que dice: ПP $\Omega M$ ambas son de barro muy bien conservadas, un jarro de la misma materia con bajos relieves que es el $n .^{\circ} 15$ una tinaquita de barro $n^{\circ} 16$ y una lapida que pongo para que con el Sr. Ramis averigue su sentido.

\section{ANTESTIA}

ASITIO . AVE.

ET . VAE. ${ }^{10}$

Me han remitido tambien algunas monedas que necesitan de limpiar como las otras.

Esta lapida dice que se halló junto a una urna de vidrio que contenia las cenizas de un Romano Balear y cuando por las azas la conducian desde el cementerio á su casa les quedaron estas en las manos que exparcieron las cenizas por el suelo de entre las cuales se distinguió una moneda consular de plata con cascarilla y siendo de cobre en lo interior. Dice tiene otra lapida en 3 pedazos la que dice me remitira en otra ocasion y que deja de enviarme otros monumentos por estar algo extropeados efecto del poco cuydado que tienen á estas cosas la gente rustica y aldeana como que aprecian las cosas por su valor extrinseco. Pero

10 Incluida en "Carta histórico-crítica" citada, y descrita despues por Joaquín María Bover, José Maria Quadrado, Emil Hübner (ClL. II, núm. 3674) y Veny, ClB, 1965, núm. 80 . 
me canso y cuando nos veamos que sera pronto hablaremos à la larga sobre el particular.

Memorias á mi Sra. su Madre, hermano y amigos y en escribiendo al Dr. Ramis quisiera que me pusiese á su disposición manifestandole el deseo que tengo de ser uno de sus amigos y servidores.

como siempre de V.

Ant. ${ }^{\circ}$ de Furió y Sastre

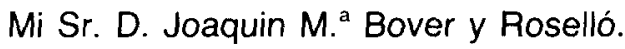

$P$. D. Esos diseños son en todo exactos á los originales que tengo en mi poder que como llevo dicho vera $V$. cuando regrese á esa. En cuanto á noticias no he cuydado de recojerlas supuesto que he estado siempre ocupado en las antiguedades y que nosotros tenemos cuanto se puede desear de estos Pueblos.

De Furio (rubricado)

Al dorso hay una anotación que dice; "recibida en 23 diciembre contestada en 25 del mismo". 